\title{
A SEX-CHROMOSOME HYBRID ZONE IN THE GRASSHOPPER PODISMA PEDESTRIS (ORTHOPTERA: ACRIDIDAE)
}

\author{
GODFREY M. HEWITT \\ School of Biological Sciences, University of East Anglia, Norwich NR4 7TJ
}

Received 2.vi.75

\section{SUMMARY}

\begin{abstract}
Podisma pedestris exists as both an XO and neoXY form in the Southern French Alps. These chromosome types are shown to be contiguously allopatric and hybrid populations have been located in several places. Hybridisation appears to be occurring freely, but the hybrid zones are quite narrow. In several places the two distributions are separated by geographic barriers such as high mountain ridges and lowlands. The history of this XY chromosomal race is discussed in the light of the genetic dynamics of hybrid zones and the biogeography of this situation. Its origin is probably post-glacial, and it may be extending its range as a salient in one region. A comparison of the properties of similar cases indicates that the formation of such chromosomal races may be a frequent event in relatively immobile species that are subjected to isolation and expansion by major climatic and ecological changes.
\end{abstract}

\section{INTRODUCTION}

ANY species shown to contain distinct chromosomal " races" with allopatric or parapatric distributions arouses considerable interest. Such polytypic situations are in contrast to polymorphisms, where the different homozygotes and heterozygotes exist sympatrically, and their study should throw light on the causal distinctions between the two types of intra-specific variation. These situations are also suggestive of incipient speciation, with properties such as lower hybrid fitness and reduced gene flow. Consequently the comparison of their detailed ecological cytogenetics and that of apparently recent sibling species may also clarify the role that chromosomes play in speciation. However, because of the labour involved in plotting cytogenetic distributions, only a few examples of this phenomenon have been clearly delineated. The two classic cases are in the South Australian morabine grasshoppers of the viatica group (White et al., 1967; White, 1974), and in Western North American annual flowering plants of the genus Clarkia (Lewis, 1966, 1973). Other examples are reported in grasshoppers, stick insects, lizards and a variety of small rodents (e.g. Nadler, 1968; Thaeler, 1968, 1974; Patton, 1969a, 1973a; Wahrman et al., 1969; Wahrman and Goitein, 1972; Hall and Selander, 1973; Wahrman and Gourevitz, 1973; White, 1973; Craddock, 1974; Nevo et al., 1974).

A promising allopatric chromosomal variation was found in the grasshopper Podisma pedestris (Acrididae: Catantopinae) in the South Western Alps of Europe (John and Hewitt, 1970; Hewitt and John, 1972). This wingless species probably invaded Western Europe from central Russia (where it is currently very abundant) during the quaternary glaciations; it is 
now found throughout the Alps and Northern Appenines, where it occurs above about $1800 \mathrm{~m}$ in the south and above $1000 \mathrm{~m}$ in the north of this region. Most populations possess the standard acridid karyotype with $2 n \widehat{\delta}=22+\mathrm{X}$, all are telocentrics and there is an XO/XX sex chromosome mechanism. However, a region of exclusively neoXY populations was discovered in the Alpes Maritines, where the original $\mathrm{X}$ chromosome has become fused with an autosome to give a large metacentric neoX and the unattached autosomal homologue has become a neoY chromosome (figs. 1 and 2). In the male the fused autosome has a restricted chiasma formation compared with its free progenitor. The species also contains supernumerary chromosomes of two types that differ in size and stability (figs. 1 and 2), and it is possible that their origins may be connected with this sex chromosome variation. In the last 3 years an attempt has been made to define more accurately the limits of the neoXY distribution and to look for possible contact zones with the $\mathrm{XO}$ distribution.

\section{Materials AND methods}

In the mountainous environment of the higher Alpes Maritimes, populations of Podisma pedestris are often small and isolated. Consequently, in order not to distort the situation, the sampling was adjusted to suit the population size. For males the sample size varied between 1 and 30 , and for females between 1 and 10. The "young adult" season is quite short in these alpine populations and the loss of adult females represents a considerable reduction in the populations' reproductive capability. However, it is necessary to take some females, since with this sex chromosome variant only the female may be heterozygous for fused and unfused X's (XA: $\widehat{X A}$ ) (figs. 6 and 7), and males are either XO or neoXY (XA:A or XA:A) (figs. 1 and 2). The presence of $\mathrm{XA}: \mathrm{XA}$ females is proof that the $\mathrm{XO}$ and neoXY chromosome races have hybridised. The testes of the males were fixed in 3:1 alcohol-acetic and given a preliminary examination in the field using temporary lacto-propionic orcein squash preparations to locate the geographical regions of contact. A full cytological examination was performed on the remaining fixed material on return to the laboratory. Both last instar and young adult males were used. The young adult females were injected intra-abdominally with 0.05 per cent colcemid in insect saline and left overnight before the ovarioles and enteric caecae were removed and fixed in 3:1 alcohol-acetic. These were examined by lacto-proprionic orcein squashes on return to the laboratory, since this is not easily performed in the field. The physical and vegetational aspects of each population's environment were also noted. Podisma was usually found in open grassy slopes with occasional wortleberry, thistle and Great Yellow Gentian.

\section{Current distribution AND hybrid zones}

Figure 8 summarises our knowledge to date of the distribution of the neoXY race from the analysis of some 90 populations in this region. The high altitude regions are shaded and may be taken as a guide to the distribution of the species, which is generally XO. Most populations come from the 
Frg. 1.-A cell in 1st meiotic metaphase in an XO male with a large B chromosome. FIG. 2.-A lst meiotic metaphase in a neoXY male with three small B chromosomes. FIG. 3.-A neoXY bivalent in early diplotene showing diffuse extension of distal region of the original $\mathrm{X}$. The $\mathrm{B}^{\mathbf{1}}$ chromosome does not show this.

Fig. 4.- Slightly later in an XO male with a $\mathrm{B}^{1}$ chromosome.

Fig. 5.-Early pachytene in an $\mathrm{XO}+\mathrm{B}^{1}$ male; the $\mathrm{X}$ and $\mathrm{B}$ are closely associated and one (most probably the $\mathrm{X}$ ) has a less condensed distal region.

Fig. 6.-An ovariole mitosis from a hybrid (XA:XA) female.

FIG, 7.-An ovariole mitosis from an unfused (XA:XA) female with a large B chromosome that is slightly smaller than the $\mathbf{X}$. One $\mathbf{X}$ is partially allocyclic.

(The bar scale equals $10 \mu$ ) 


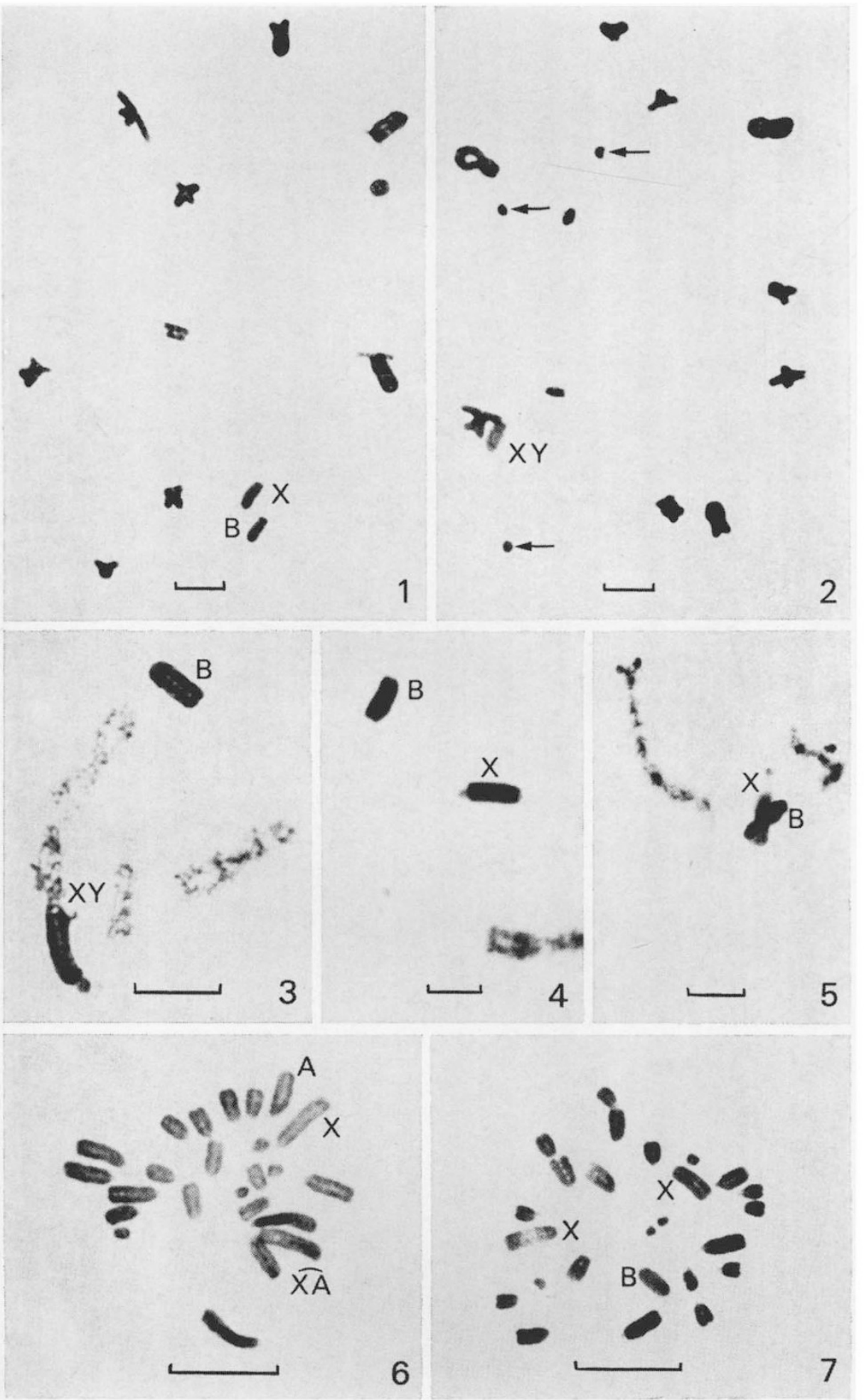


areas 1 to 6 where the $\mathrm{XO}$ and neoXY distributions approach closely to each other, and in some cases produce hybrid populations.

Area 1. A mixed population was located $3 \mathrm{~km}$ west of the village of Barles (Route N100A) near the Bergerie de Chine. This sample contained 2 XO males and 9 XY males, 5 XA:XA females and 1 XA:XA female hybrid. This population seemed well established. To the south and east the

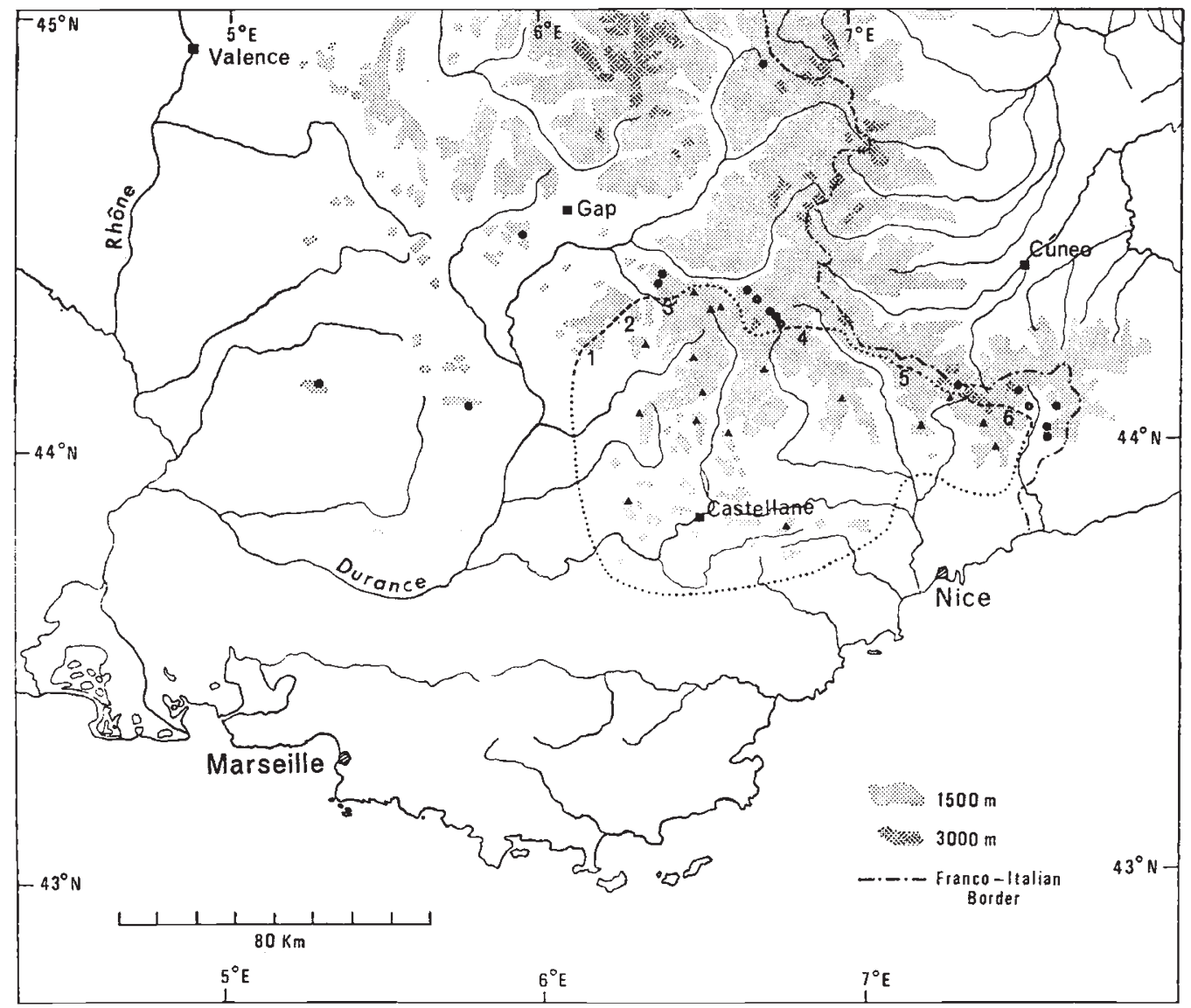

Fic. 8.-A map of the Southern European Alps showing the distribution of the XO (circles) and neoXY (triangles) races of Podisma pedestris in this region. Where the neoXY distribution line is more heavily dashed, the juxtaposition of the two races is accurately determined.

populations are completely neoXY/neoXneoX in constitution; one such neoXY population is just $300 \mathrm{~m}$ to the east of the hybrid population. About $2 \mathrm{~km}$ to the NW over the Col de Clapouse is a completely XO/XX population and all populations collected to date to the north and west are also completely XO.

Area 2. A mixed population was located $4.5 \mathrm{~km} \mathrm{SW}$ of Seyne (Route N100) on a bluff above Negron farm. This contained $7 \mathrm{XO}$ and $2 \mathrm{XY}$ males $3 \mathrm{XA}: \mathrm{XA}$ females and $1 \mathrm{XA}: \widehat{\mathrm{XA}}$ female hybrid. Below and $500 \mathrm{~m}$ to the 
SE the populations are completely neoXY/neoXneoX. The species was quite sparse in this region.

Area 3. Two populations, one entirely $\mathrm{XO} / \mathrm{XX}$ and the other neoXY/ neoXneoX were located $3.5 \mathrm{~km}$ apart; the former is $5 \mathrm{~km}$ due east of Seyne (Route N100) and the latter $6.5 \mathrm{~km} \mathrm{SE}$ of Seyne. Grasshoppers were common in both populations. To the north the populations are $\mathrm{XO}$ and to the south they are neoXY. The terrain between these two chromosomally different populations is rugged and largely wooded. While no mixed population was discovered here it is possible that one might be found with further intensive searching of the region.

Area 4. Podisma is not common in these wetter mountain regions but an $\mathrm{XO} / \mathrm{XX}$ population and a neoXY/neoXneoX population were found $7 \mathrm{~km}$ apart west of St Etienne de Tinée (Route N205). The former is north of Bois de Sestrière $3 \mathrm{~km}$ WNW of St Dalmas le Selvage, the latter is $6 \mathrm{~km} \mathrm{SW}$ of St Etienne. The terrain in between is rocky or wooded and largely inhospitable to Podisma, but a mixed population might be found on the slopes east of the formidable Fort Carra (2900 m).

Area 5. The change from XO to neoXY sex mechanism appears to coincide with the Franco-Italian border on the Col de la Lombarde (2350 $\mathrm{m}$ ). A neoXY population was located $500 \mathrm{~m}$ south and below the Col, and the first grasshoppers encountered $1 \mathrm{~km}$ north of the Col had the unfused $\mathrm{X}$. At this altitude in this region, Podisma is very scarce. Populations south of this were all neoXY.

Area 6 . This region is the most closely studied to date; in addition to the populations shown in fig. 8 another 38 populations have been analysed. The detailed distribution of chromosome types in this region is shown in fig. 9 . The contact zone runs broadly NW to SE but because of the mountainous nature of the environment the distribution of the species and of the two chromosomal types is complex. Three mixed populations have been located. (1) The most southern of these is at $1900 \mathrm{~m}$ on the south facing slopes north of La Minière de Vallaure. The sample contained 10 XO males, 1 neoXY male, $2 \mathrm{XA}$ : XA females and $1 \mathrm{XA}: \mathrm{XA}$ female hybrid. The occasional males that were caught $100 \mathrm{~m}$ or so both up and down from this main concentration were all XO. On the slopes below and along the Vallon de Minière are several completely neoXY populations. About $300 \mathrm{~m}$ to the east of this mixed population, over the shoulder of Les Mesces on the east facing slopes, is an XO population also at $1900 \mathrm{~m}$. Another XO population was found higher up the slope to the north of this mixed population at $2100 \mathrm{~m}$. The terrain is very steep in between these populations, but it is not completely inhospitable to Podisma and it seems possible that a small amount of insect dispersal between the chromosome races could occasionally occur. (2) The second mixed population is $2.5 \mathrm{~km}$ to the north on the southern slopes of the Vallon de Fontenalbe at $1750 \mathrm{~m}$. It contained $10 \mathrm{XO}$ males, 2 neoXY males, 2 XA:XA females, 1 XA:XA hybrid female and 2 XA: XÂ females. About $800 \mathrm{~m}$ to the east at the mouth of the valley is an XO population and there is another about $800 \mathrm{~m}$ away on the northern slopes of the valley. (3) The third mixed population is $1.5 \mathrm{~km}$ up the valley to the WSW at $2000 \mathrm{~m}$. It

contained 12 XO males, $1 \mathrm{XA}: \mathrm{XA}$ female, and $2 \mathrm{XA}: \mathrm{XA}$ hybrid females; individuals were quite common. To the NW $1.5 \mathrm{~km}$ is an XO population 


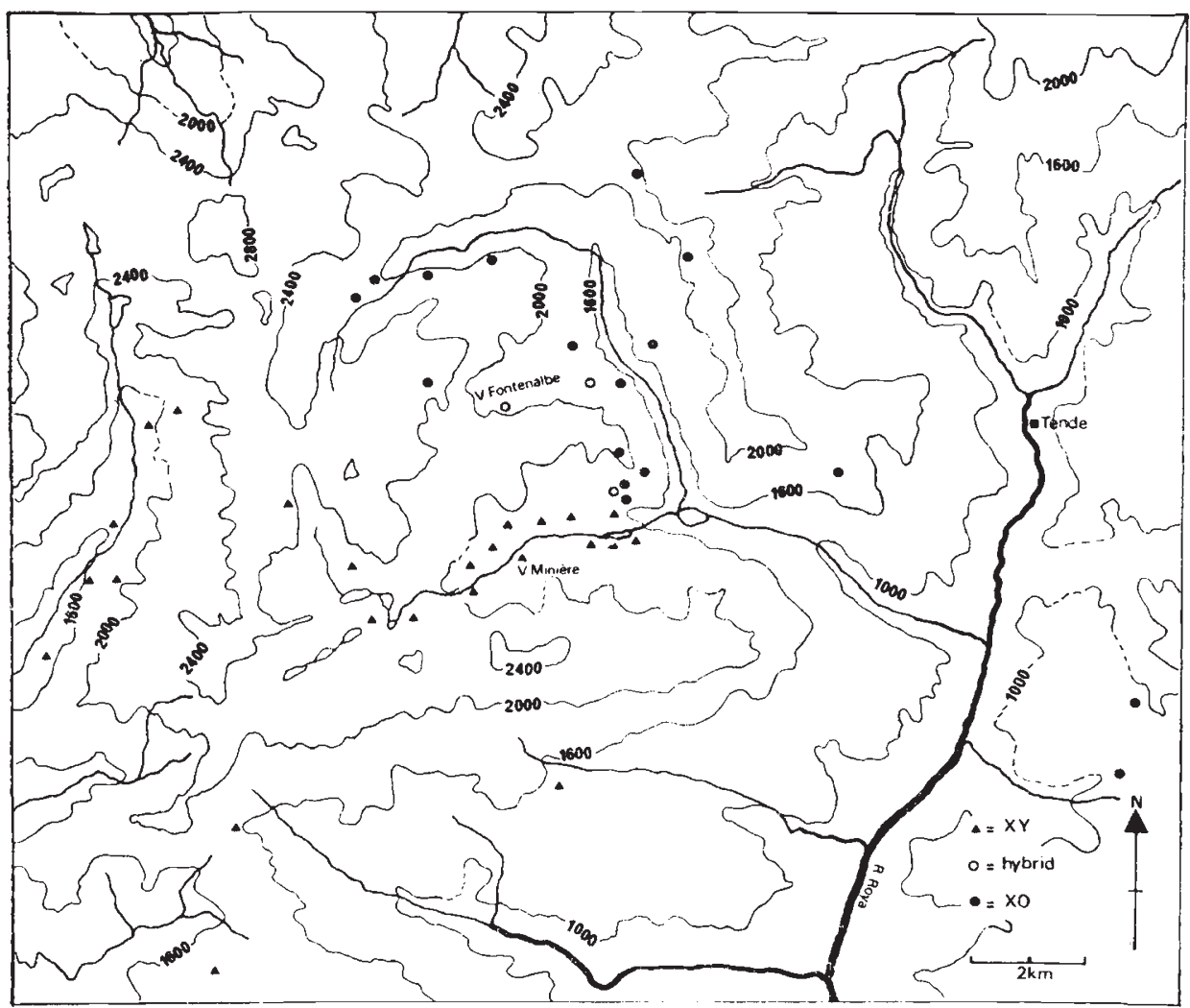

Fig. 9.-A detailed map to show the location of the XO and neoXY populations in Area 6. Altitude is in metres, and hybrid populations in the neoXY salient are indicated.

and to the north and east of the Fontenalbe Valley the populations are XO. Consequently these two mixed populations appear as an intrusion into $\mathrm{XO}$ territory.

Thus three areas (1,2 and 6) have been located in which the $\mathrm{XO}$ and neoXY distributions meet, and from the frequency of XA: XA females there is apparently common hybridisation. These hybrid populations are quite localised with homokaryotypic populations nearby. At Les Mesces in Area 6 the zone does not appear to have moved more than $1 \mathrm{~km}$ in either direction over a period of 2 years. Collections previous to that which located the hybrid population, found $\mathrm{XO}$ and neoXY homokaryotypic populations about $1 \mathrm{~km}$ either side of the contact location, and these were the same chromosomally at the later collection. In the three other Areas (3, 4 and 5) the two homokaryotypic distributions have been shown to approach within a very few kilometres of each other, but the intervening inhospitable terrain seems largely responsible for the absence of hybrid populations.

\section{PAST DEVELOPMENT OF THE DISTRIBUTION AND ZONES}

The fact that the hybrid populations are so localised argues strongly that the two chromosomal arrangements (unfused $\mathrm{XA}$ and fused $\widehat{\mathrm{XA}}$ ) cannot 
coexist in equilibrium; but proof of this and the reasons for it must lie in field and laboratory experiments. The most probable reason is that the hybrid has reduced fitness. Consequently the initial mutation must pass through a stage as relatively unfit female heterozygotes before fit mutant homozygotes are produced. This requires the relaxation of intraspecific competition provided by at least local and temporary isolation due to a reduction in population numbers. If the mutant homozygote is considerably fitter than the basic homozygote, then the "barrier" of heterozygote unfitness may be overcome more readily, and this may require only a short and very local population crash. However, it seems most unlikely that the centric fusion itself would produce any marked advantageous phenotypic effect by comparison with chromosome rearrangements in general and those involving centric heterochromatin in particular. But whatever may be the relative fitnesses and fertilities of the two homokaryotypes, the optimum conditions for fixation of the neoXY karyotype are in an isolate with severe bottlenecks in population numbers.

The area currently occupied by Podisma pedestris in the southern Alps was covered by ice, snow and tundra at the end of the last ice age, perhaps as little as 10,000 B.P. when there probably was a final short cold spell. Consequently the most likely origin of the neoXY form was as a mutation (in an isolate) in Provence to the south of its present distribution at, or just before this time. With the post-glacial amelioration the neoXY form could spread northwards and upwards into the areas opened up by the retreat of the ice and tundra. At the same time the lowland regions to the south, west and east would become too warm for it. The XO Podisma pedestris populations would similarly follow the retreat of the ice into the Alps.

When the two forms met, a variety of things could have happened (see Key, 1974 for a discussion of zones in morabine grasshoppers). If the hybrid heterokaryotype has reduced fitness or fertility, then the situation has the necessary conditions for the formation of a stable hybrid zone, and the greater the reduction in hybrid fitness the narrower will be the zone. Podisma pedestris is wingless and therefore not very mobile; it also has a relatively unsophisticated courtship (Jacobs, 1953) and consequently mating discrimination is unlikely. These two attributes will also allow the zone to remain narrow. In such a situation the zone will advance if one homokaryomorph is fitter than the other, and it will remain steady when the two confronting homokaryomorphs have the same fitness. Consequently the distribution of the neoXY in Podisma pedestris may have expanded or contracted following its contact with the $\mathrm{XO}$ form.

If the two karyomorphs do have different fitnesses then one might expect their equilibrium distributions to be correlated with different environments, with the zone at the null point for selection. The detailed distribution in Podisma pedestris does not obviously fit this possibility. The climate and terrain vary greatly along the northern edge of the neoXY distribution; and in Area 6 both forms occur in various habitats over a range of altitudes and aspects.

While the region of parapatry does not appear at present to be determined by "ecological" changes it seems to be "physically" limited in several places. This is due to unsuitable habitat (Areas 3 and 4) and high or low altitude (Area 5 or 6 ). Despite such great geographic barriers to dispersal and contact, the zone does not follow such barriers along its entire length, 
e.g. Areas 1, 2 and 6. To detect any movement of the hybrid zone it is necessary to follow carefully the contacts in these regions. If the zone is moving then this will indicate a clear selective advantage of the advancing chromosome type.

In its past expansion the neoXY form must have crossed regions which are presently barriers to the species movement. Firstly, in the south of its range there are several high altitude "islands" of Podisma pedestris isolated by surrounding low altitude regions. Secondly, Areas 1 and 2 are probably completely isolated from the rest of the neoXY distribution to the east and this argues for the survival of both $\mathrm{XO}$ and neoXY on this outcrop for some considerable time, perhaps since the post-glacial amelioration some 8000 years ago. Thirdly, the neoXY form would seem to have crossed the Col d'Allos (2240 m, Area 3) in the past, but not spread far. In Area 5 the two forms approach very closely to either side of the Col de la Lombarde $(2350 \mathrm{~m})$; perhaps it has only recently been reached by the neoXY form. Fourthly, in order to reach the Vallon de Miniére in Area 6 the neoXY form must either have crossed the Cols to the south of the valley or else approached from the east at low altitude up the valley from the south of St Dalmas. This latter route seems unlikely since the regions around it contain XO grasshoppers. For Podisma to cross these higher cols would require a climatic amelioration of 100 to $200 \mathrm{~m}$ that lasted for several generations. Such short-term changes are known to occur from insect data and leave little trace in the data from the more slowly colonising flora (Coope, 1970).

The two hybrid populations in the Vallon de Fontenalbe in Area 6 is

an interesting discovery, for these appear to be a salient of the fused $\widehat{\mathrm{XA}}$ into unfused territory. One would expect such protrusions of a hybrid zone to be overwhelmed from three sides by mating with the opposing karyotype and the production of unfit hybrids. This should lead to a smooth hybrid zone in the absence of ecological and physical barriers. There are clearly some barriers in this region, but Podisma pedestris is sufficiently abundant around the salient to allow a study of its dynamics and zonal movement.

The phenomenon of "reproductive swamping" has been recognised by several workers (e.g. Lewis, 1961; Key, 1968, 1974; White, 1968, Bazykin, 1969). Between two forms of equal fitness the more frequent form eliminates less frequent one because their hybrid is less fit. If one homozygote is fitter than the other then proportionately fewer of the fitter form are required at the null frequency. In a finite population the equilibrium of course is unstable. Glearly it is a war of attrition where superior number win the day, and Whitten (pers. comm.) has modelled the situation on a plane with a density gradient of the species. The hybrid zone moves down the density gradient towards lower densities; the form with more individuals advances until a region of even density or a trough of reduced density is reached. The southern edge of the Alps provides the best environment for Podisma pedestris, and the largest populations are found in the area occupied by the neoXY form (Dreux, 1962). This is reason to expect the zone to move northward, with the neoXY expanding at the expense of the XO. This general tendency may of course be thwarted or reversed by local conditions to produce temporarily stable salients and intrusions. These could survive until environmental reversals reduce their numbers sufficiently to allow colonisation by the surrounding form. 
The pivotal factor in the development of a stable narrow hybrid zoneor tension zone (Key, 1974) - is some form of reduced hybrid fitness. It is generally argued that if there is no reduction in hybrid fitness, then when the two forms meet they will introgress and no clear hybrid zone will develop. This is true given a period of time long enough for dispersal to effect the mixing. However, in a situation where the species has a patchy and dissected distribution, with frequent population crashes and only occasional gene flow between populations, it seems possible that the distributions of the two forms may remain largely separate with a fairly narrow zone of contact for some time. While such a metastable state seerns unlikely it must be borne in mind as a possible explanation of these and similar zones until clearly disproven.

In general the foregoing evidence supports the idea that the neoXY form has expanded its range in the past 10,000 years and crossed some barriers which are at present impassable. Some deep valleys and high mountains have been and will remain barriers for some considerable time. The current narrow hybrid zone could well be relatively static in some places but on the move in others. Moreover the expectations of these different possibilities are clearly distinguishable by further research.

\section{B CHROMOSOMES}

Two primary types of $\mathbf{B}$ chromosomes-large ( $\left.\mathbf{B}^{1}\right)$ (fig. 1 ) and small $\left(\mathbf{B}^{\mathrm{s}}\right)$ (fig. 2)-have been found in Podisma pedestris from this region (Hewitt and John, 1972; Hewitt, 1973), and one may ask if there is any relationship between them and the hybrid zone. Malorientation in meiosis of a female hybrid could generate polysomy for the $\mathrm{X}$, and $\mathrm{B}^{1}$ could be an escaped $\mathrm{X}$. The large $B$ is telocentric and about the same size as the $X$ chromosome. Indeed in most male cells the two are difficult to distinguish on size or allocycly, unless of course the $\mathrm{X}$ is attached in the neoX form. There is, however, some difference in condensation and appearance in pachytene, which may persist later into meiotic prophase. In neoXY males the distal end of the attached $\mathrm{X}$ is diffuse and extended (fig. 3), and sometimes associated with the remains of a nucleolus in pachytene. If the $B$ chromosome is an escaped X chromosome (Hewitt and John, 1972; Hewitt, 1973) then this difference may be due either to inactivation or to a small deletion of this region in the supernumerary. In an $\mathrm{XO}$ male with a large supernumerary it is not possible to be sure whether the $X$ or the $B$ is diffuse in this region (figs. 4 and 5), but by analogy with the neoXY behaviour it is likely to be the $\mathrm{X}$ chromosome rather than the derived $\mathrm{B}$ chromosome. The large $\mathrm{B}$ was found in two females (fig. 7) and appeared to be slightly shorter than the $\mathrm{X}$ chromosomes.

Of the 90 populations studied in this region, 21 possessed the large $\mathbf{B}$ chromosome. The frequency of $\mathbf{B}^{1}$ in males in these populations varied from the odd individual to half of the population, and the overall frequency was $28 / 112=0.22$. In females from these same populations it was only $2 / 47$ $=0.04$. This less frequent occurrence in female ovariole tissue as compared with male testes may be due to several causes. (1) The supernumerary may be generated more frequently, or else accumulated in the male germline; this seems unlikely as the $\mathrm{B}^{1}$ is stable in spermatogonial mitoses. (2) The supernumerary may be lost preferentially from the somatic tissues; this is 
reported for smaller B chromosomes in the grasshoppers Atractomorpha bedeli and Gonista bicolor (Sannomiya, 1973, 1974). (3) The female may be less tolerant of supernumeraries than the male, perhaps because the male may be able to " inactivate" the extra chromosome. A fourth possibility-that of preferential segregation of the $B$ and $X$ to the opposite poles in male meiosis thereby giving more male offspring with B's-can be discounted since the B's meiotic segregation is random with respect to the $\mathrm{X}$ in Podisma.

Only 5 of the 90 populations possessed the small Bs chromosome, which was unstable at higher numbers in the individual. Here also the females had a lower frequency of supernumeraries than the males; $91 / 20=0.05$, ${ }^{1} 10 / 59=0.17$ in those populations with B's. One population possessed both large and small supernumeraries in different individuals.

The distribution of B chromosomes does not appear to be associated with the hybrid zone specifically; however the three females with supernumeraries were in two of the mixed populations. The large B chromosome is found in both XO and neoXY populations and appears to be distributed in an arc of the western, southern and eastern parts of the grasshoppers' distribution in the Alpes Maritimes. It is absent from the central and northern parts of this area. This southern fringe of Podisma pedestris in the Alps is also the region of greatest aridity and largest population numbers (Dreux, 1962), and thus the $\mathrm{B}^{1}$ chromosome appears associated with favourable environments as is the case in several other species (Hewitt and Brown, 1970; Westerman, 1975).

The large B chromosome does not effect chiasma frequency in the individuals carrying it. This was previously tested in three populations with sufficient numbers of $\mathrm{OB}$ and $\mathrm{BB}$ individuals (Hewitt and John, 1972), and a further two populations have now been tested with the same negative result.

\section{General discussion}

Parapatric chromosomal races in several animal species have many features in common with Podisma (table 1). All are species of low mobility and dispersal, which will encourage isolation and retard introgression. Usually centric fusions or fissions are involved, and only occasionally are other rearrangements concerned. This preponderance of centric rearrangements may be due to (1) ease of detection, or (2) more frequent occurrence or (3) more ready establishment in an isolate. Where mitotic cells are used for analysis of the karyotype, as is the case in most mammalian studies, then the first explanation probably applies. But in the insect examples the examination of meiosis in the hybrids has shown in two species the involvement of translocations in hybrid zones. Even so fusions and fissions are more common in insects. In grasshoppers there is no evidence as yet to suggest that centric rearrangements occur more frequently as spontaneous mutations. However, their properties in hybrid meiosis are intermediate between inversions, which usually produce little sterility and frequently show polymorphism, and translocations which usually produce considerable sterility and therefore cannot exist with the parent karyotype. We may also note that of over 100 derived sex chromosome systems in the Orthoptera only two possible polymorphic cases have been reported. They are in Hesperotettix viridis collected from Marathon Texas (McClung, 1917) and Perixerus squamipennis (Helwig, 1941); both could be examples of polytypy and require re-examination. There are, however, several cases where races differ by sex 


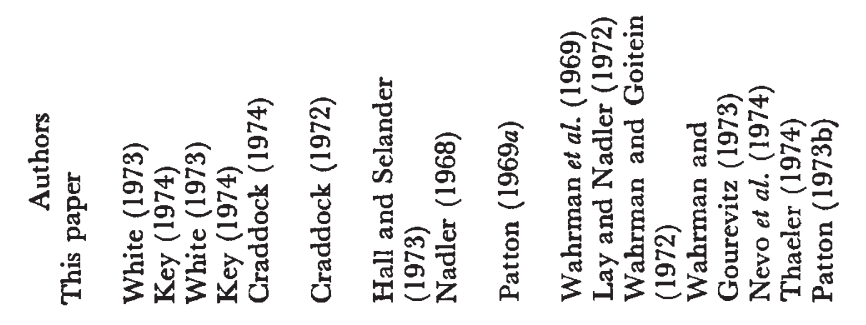

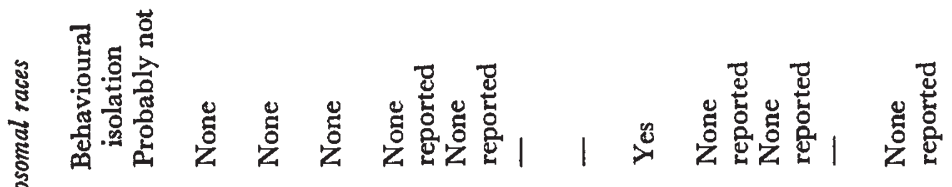

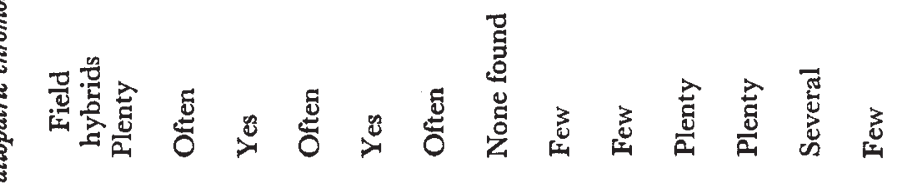

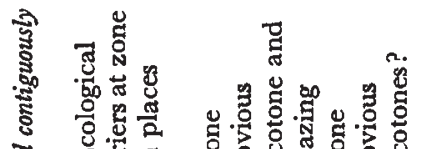

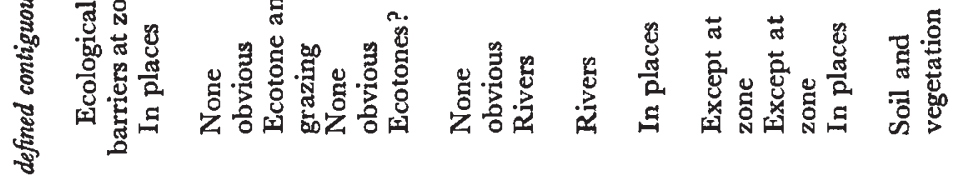

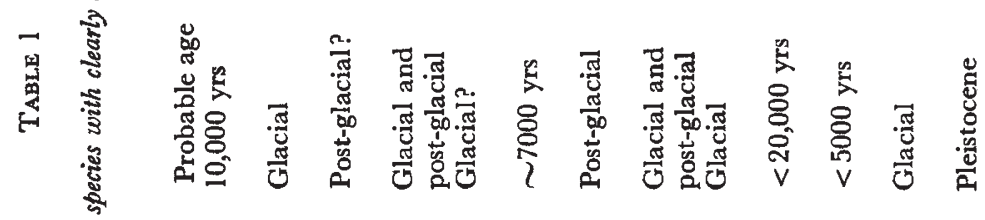

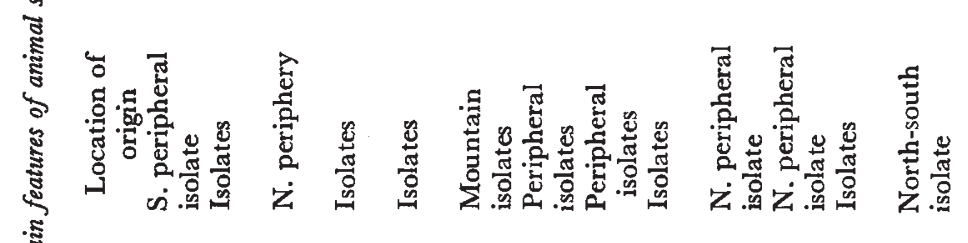

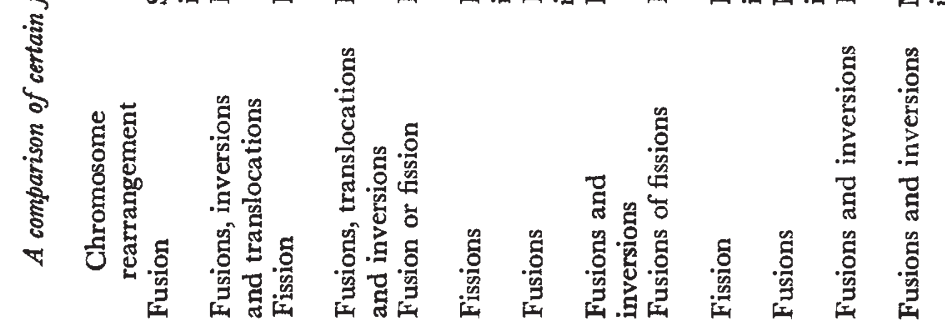

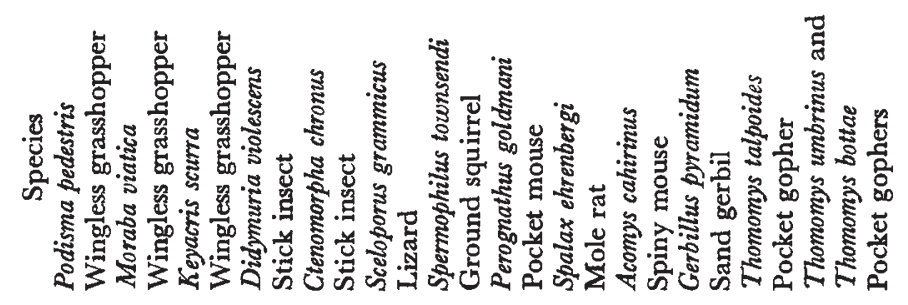


chromosome rearrangements, which emphasise the apparent inability of such changes to persist as polymorphisms.

The origin and establishment of these chromosomal changes (table 1) most probably occurred in small peripheral isolates or internal refugia, which were created by the cool conditions of the ice ages or the warm conditions of the post glacial climatic optimum. As these restrictive climatic conditions ameliorated the isolates expanded until their distributions met. In some cases the present positions of the contact regions were influenced and determined by ecological and physical barriers to dispersal, and in some the races probably possess adaptations to different conditions.

Some of the hybrid zones are probably less stable than others. The mole rat Spalax ehrenbergi is the only case where behavioural differences are known to restrict mating between different races, and this should allow a degree of sympatry in environments to which the races are equally suited. The hybrid zone in the sand gerbil Gerbillus pyramidum is quite wide, and perhaps the north and south forms are slowly intergrading at this contact since they are separated geographically elsewhere. The process of intergradation following chromosomal differentiation in isolation has apparently occurred in other organisms, such as Thomomys bottae, a pocket gopher (Patton, 1973a), where there has not been a suitable combination of low vagility, compatible courtship, hybrid disadvantage and ecological restraints to produce a stable hybrid zone.

There are several reports of other similar species, and this suggests that many other allopatric and parapatric chromosomal races have been produced by a history of recent isolation and expansion due to climatic reversals, e.g. the pocket mouse Perognathus pencillatus (Patton, 1969b), the pinion mouse Peromyscus truei (Hsu and Arrighi, 1968), the tuco-tucos in the genus Ctenomys (Reig and Kiblisky, 1969), the feral mouse Mus musculus (Gropp et al., 1972), the lesser mole rat Spalax leucodon (Raicu et al., 1973) and the pocket gopher Geomys bursarius (Selander et al., 1974). In other cases, such as jirds of the genus Meriones (Lay and Nadler, 1969) and the mole cricket Gryllotalpa (Nevo and Blondheim, 1972), the isolation appears to have produced forms that are somewhat more reproductively or behaviourally distinct. These and similar cases should then be capable of sympatry in suitable environments.

Several subspecies of Podisma pedestris have been erected to describe the insects in the Alps and northern Appenines, and closely related taxonomic species have been described from the mountains of Italy and Iberia. Clearly their isolation in montane Europe has generated considerable morphological differences. However the XA fusion form can only be considered as a race at most, since gene flow is possible through the hybrid zone and the two forms do not seem capable of coexistence. In cases such as this where there is apparently no premating isolation, it seems unlikely that reinforcement will occur at the zone to overlay and augment any post-mating restriction on gene flow. Tension zones, once formed, could therefore be relatively permanent features, between climatic changes, and need not progress to full species discontinuities. Several of these founder karyotypic revolutions have occurred in the viatica group of morabine grasshoppers (White et al., 1967), and the hybrid zones they produced have coalesced in a number of places (Key, 1968; White, 1968). Where two parapatric forms are separated by 
such multiple differences, the hybrids may be completely infertile so that no gene flow is possible - as with viatica 17 and viatica $24 X Y$ (Key, 1974). This particular parapatric juxtaposition has been in existence for at least 9000 years when Kangaroo Island was separated from the mainland of South Australia by the post-glacial rise in sea level. In Podisma pedestris the ease of hybridisation and extent of gene flow are open to experimental investigation. Along with a determination of the stability of the hybrid zone and an examination of the adaptive niches of the $\mathrm{XO}$ and neoXY races, they form the next phase in the elucidation of this phenomenon.

Acknowledgments.-I wish to express my sincere thanks to the several people who assisted in the considerable amount of field work involved, in particular Alan Jenyon and Robert Williams. The financial assistance of the Royal Society, Science Research Council and University of East Anglia at various stages in the investigation is gratefully acknowledged, Professors Bryan Clarke and Roy Davies kindly provided constructive criticism of the manuscript.

\section{REFERENCES}

BAZYKIN, A. D. 1969. Hypothetical mechanism of speciation. Evolution, 23, 685-687.

COOPE, G. R. 1970. Interpretations of Quaternary insect fossils. Ann. Rev. Ent., 15, 97-120. GRADDOCK, E. M. 1972. Chromosomal diversity in the Australian Phasmatodea. Aust. $\mathcal{F}$. Zool., 20, 445-462.

GRADDOcK, е. м. 1974. Chromosomal evolution and speciation in Didymuria. In Genetic Mechanisms of Speciation in Insects (ed. M. J. D. White), pp. 24-42. Australia and New Zealand Book Co.

DREuX, P. 1962. Recherches écologiques at limnographiques sur les Orthoptères des Alpes Francaises. Thèses presentés a la Faculté des Sciences de l'Université de Paris, 323-766. GROPP, A., WINKING, H., ZECH, L., AND MULleR, H. 1972. Robertsonian chromosomal variation and identification of metacentric chromosomes in feral mice. Chromosoma (Berl.), 39, 265-288.

HALL, W. P., AND SELANDER, R. K. 1973. Hybridization of karyotypically differentiated populations in the Sceloporus grammicus complex (Iguanidae). Evolution, 27, 226-242.

Helwig, E. R. 1941. Multiple chromosomes in Philocleon anomalous (Orthoptera:Acrididae). 7. Morph., 69, 317-327.

HEWITT, G. M. 1973. The integration of supernumerary chromosomes into the Orthopteran Genome. Cold Spring Harbor Symp. Quant. Biol., 38, 183-194.

HEWITT, G. M., AND BROWN, F. M. 1970. The B-chromosome system of Myrmeleotettix maculatus. V. A steep cline in East Anglia. Heredity, 25, 363-371.

HEWITT, G. M., AND JOHN, B. 1972. Inter-population sex-chromosome polymorphism in the grasshopper Podisma pedestris. II. Population parameters. Chromosoma (Berl.), 37, 23-42.

HSU, T. G., AND ARRighi, E. E. 1968. Chromosomes of Peromyscus (Rodentia, Cricetidae). I. Evolutionary trends in 20 species. Cytogenetics, 7, 417-446.

JACOBs, w. 1953. Verhaltensbiologische Studien an Feldheuschrecken. Z. Tierpsychol. Suppl. 1, 1-228.

JOHN, B., AND HEWTTT, G. M. 1970. Inter-population sex-chromosome polymorphism in the grasshopper Podisma pedestris. I. Fundamental facts. Chromosoma (Berl.), 31, 291-308.

KEY, K. H. L. 1968. The concept of stasipatric speciation. Syst. Zool., 17, 14-22.

KEY, к. H. L. 1974. Speciation in the Australian Morabine Grasshoppers. In Genetic Mechanisms of Speciation in Insects (ed. M. J. D. W.hite), pp. 43-56. Australia and New Zealand Book Co.

LAY, D. M., AND NADLER, C. F. 1969. Hybridization in the rodent genus Meriones. I. Breeding and cytological analyses of Meriones shawi $(\$) \times$ Meriones libycus $\left({ }^{\Uparrow}\right)$ hybrids. Cytogenetics, $8,35-50$.

LAY, D. M., AND NADLER, C. F. 1972. Cytogenetics and origin of North African spalax (Rodentia:Spalacidae). Cytogenetics, 11, 279-285.

LEWIS, H. 1961. Experimental sympatric populations of Clarkia. Amer. Natur., 95, 155-168.

LEWIS, $\boldsymbol{H}$. 1966. Speciation in flowering plants. Science, 152, 167-172.

LEWIS, H. 1973. The origin of diploid neospecies in Clarkia. Amer. Natur., 107, 161-170. 
MCCLUNG, c. E. 1917. The multiple chromosomes of Hesperotettix and Mermiria. F. Morph., 29, 519-605.

NADLER, C. F. 1968. The chromosomes of Spermophilus townsendi (Rodentia:Sciuridae) and a report of a new subspecies. Cytogenetics, 7, 144-157.

NEvo, E., AND BLONDHEIM, s. A. 1972. Acoustic isolation in the speciation of mole crickets. Ann. Entom. Soc. Amer., 65, 980-981.

NEvo, E., KIM, Y. J., SHAW, C. R., AND THAELER, C. S. 1974. Genetic variation, selection and speciation in Thomomys talpoides pocket gophers. Evolution, 28, 1-23.

Patton, J. L. 1969a. Chromosome evolution in the pocket mouse, Perognathus goldmani Osgood. Evolution, 23, 645-662.

Patton, J. L. 1969b. Karyotypic variation in the pocket mouse, Perognathus pencillatus Woodhouse (Rodentia-Heteromyidae). Caryologia, 22, 351-358.

PATton, J. L. 1973a. Patterns of geographic variation in the pocket gopher, Thomomys bottae (Eydoux and Gervais). Evolution, 26, 574-586.

PATtON, J. L. 1973b. An analysis of natural hybridization between the pocket gophers Thomomys bottae and Thomomys umbrinus in Arizona. 7. Mamm., 54, 561-584.

RAICU, P., DUMA, D., AND TORCEA, s. 1973. Chromosomal polymorphism in the lesser mole rat, Spalax leucodon. In Chromosomes Today, 4, Wiley, 383-386.

REIG, O. A., AND KIBLISKy, P. 1969. Chromosome multiformity in the genus Ctenomys (Rodentia, Octodontidae). Chromosoma (Berl.), 28, 211-244.

sannomiya, M. 1973. Cytogenetic studies on natural populations of grasshoppers with special reference to B-chromosomes. II. Atractomorpha bedeli. Chromosoma (Berl.), 44, 99-106.

SANnomiYA, M. 1974. Cytogenetic studies on natural populations of grasshoppers with special reference to B-chromosomes. I. Gonista bicolor. Heredity, 32, 251-265.

SELANDER, R. K., KAUFMAN, D. M., BAKER, R. J., AND williams, S. L. 1974. Genic and chromosomal differentiation in pocket gophers of the Geomys bursarius group. Evolution, 28, 557-564.

THAELER, c. s. 1968. Karyotypes of sixteen populations of the Thomomys talpoides complex of pocket gophers (Rodentia-Geomyidae). Chromosoma (Berl.), 25, 172-183.

THAELER, c. s. 1974. Four contacts between ranges of different chromosome forms of Thomomys talpoides complex (Rodentia:Geomyidae). Syst. Zool., 23, 343-354.

WAHRMan, J., AND Gortein, R. 1972. Hybridisation in nature between two chromosome forms of spiny mice. In Chromosomes Today, 3, Longman, 228-237.

Wahrman, J., GOrTEIN, R., AND NEvo, E. 1969. Mole Rat Spalax:Evolutionary significance of chromosome variation. Science, 164, 82-84.

WAHRMAN, J., AND GOUREvitz, P. 1973. Extreme chromosome variability in a colonising rodent. In Chromosomes Today, 4, Wiley, 399-424.

westerman, M. 1975. Population cytology of the genus Phaulacridium. Heredity, 34, 11-27. White, M. J. D. 1968. Models of speciation. Science, 159, 1065-1070.

whrre, м. J. D. 1973. Animal Cytology and Evolution, 3rd ed., Cambridge University Press.

WhITE, M. J. D. 1974. Speciation in the Australian Morabine Grasshoppers-the cytogenetic evidence. In Genetic Mechanisms of Speciation in Insects (ed. M. J. D. White), pp. 57-68. Australia and New Zealand Book Co.

WHITE, M. J. D., BLACKITH, R. E., BLACKITH, R. M., AND CHENEY, J. 1967. Cytogenetics of the viatica group of morabine grasshoppers. I. The " coastal" species. Aust. F. Zool., 15, 263-302. 